\title{
EXTENSÃO DO MÉTODO APAC AO SISTEMA CARCERÁRIO BRASILEIRO: UMA ALTERNATIVA PARA A PENA PRIVATIVA DE LIBERDADE
}

EXTENSION OF THE APAC METHOD TO THE BRAZILIAN PRISON SYSTEM: AN ALTERNATIVE FOR THE PRIVATE PENALTY OF FREEDOM

Paulo Natanael Vieira LIMA ${ }^{1}$

ISSUE DOI: $10.21207 / 1983.4225 .1003$

\section{RESUMO}

O presente artigo descreve a realidade do sistema carcerário brasileiro e a reflexão doutrinária acerca do tema. Em seguida, descreve o método de tratamento do encarcerado desenvolvido pela Associação de Proteção e Assistência aos Condenados, na tentativa de estendê-lo a todas as penitenciárias do país.

Palavras-chave: Método APAC. Sistema Penitenciário. Extensão.

\section{ABSTRACT}

The present article describes reality of the brazilian prison system and the doctrinal reflection about the theme. Afterwards will be described the treatment method of the prisoners developed and created

\footnotetext{
${ }^{1}$ Pós-graduando em Ciências Penais e em Direito Digital, Propriedade Intelectual e Gestão da Inovação pelo IEC/PUC Minas. Membro da Comissão OAB Jovem (OAB/MG). Bolsista do $2^{\circ}$ Curso de Compliance do IBCCRIM em parceria com a Universidade de Coimbra (Portugal). Atualmente integra o Grupo de Estudos Avançados do IBCCRIM em Belo Horizonte. Ex-estagiário do escritório Armond Sociedade de Advogados e do Núcleo de Correições da Superintendência Regional de Polícia Federal de Minas Gerais. Ex-integrante da Equipe de Arbitragem da PUC Minas (2017) e do Laboratório de Ciências Criminais do IBCCRIM (2018). Ex-integrante do Grupo de Estudos em Processo Penal (GEPP/UFMG), do Grupo de Estudos em Direito Ambiental (GEDA/UFMG) e do Grupo de Estudos Democracia e Direito Tributário (GEDT/UFMG). Advogado. Currículo Lattes: http://lattes.cnpq.br/0363847068096769. Contato: paulonatanael.pn@gmail.com.
} 
by the Association of Protection and Assistance for the condemned in an attempt.to extend this treatment to all penitentiaries in the country.

Keywords: APAC Method. Penitentiary System. Extension.

\section{INTRODUÇÃO}

A sanção penal ao longo do tempo adquiriu diferentes justificativas e formas, mas em todas elas havia um objetivo intrínseco para a sua aplicação, qual seja, a punição do indivíduo que praticou uma conduta reprovada pela sociedade em que estava inserido.

Nesse compasso, diferentes técnicas foram utilizadas para punir: os revolucionários franceses de 1789 aplicavam a decapitação por guilhotina, os cristãos no período da Inquisição aplicavam a pena de morte na fogueira, alguns países islâmicos a pena de apedrejamento, mas nenhuma dessas técnicas obteve tanto destaque e popularidade quanto a pena de prisão.

Utilizada como forma de controle e de correção, é considerada nos dias atuais a forma menos aviltante de execução de pena, sendo adotada como principal espécie de punição na maioria dos países, inclusive no Brasil. Ao longo do tempo, a justificativa do método prisional se alterou, imperando na atualidade a ideia de ressocialização e recuperação, considerando o infrator de uma norma jurídica um indivíduo que precisa de vigilância e cuidados especiais.

Na década de 1970, apegados a essa filosofia moderna, um grupo de indivíduos desenvolveu a Associação de Proteção e Assistência aos Condenados (APAC), detentora de uma metodologia avançada e complexa de tratamento carcerário, responsável pela diminuição brusca do número de reincidência criminal no Brasil.

No trabalho a seguir, será demonstrado como se desenvolveu a APAC e qual o cerne da metodologia por ela elaborada, ansiando pela aplicação metodológica na forma estatal de encarceramento, no intuito de efetivá-la como política de ressocialização.

\section{APAC: SURGIMENTO, MÉTODO E EMBASAMENTO LEGAL}




\section{$2.1 \quad$ SURGIMENTO E PROPÓSITOS DA APAC}

A Associação de Proteção e Assistência aos Condenados (APAC) é um sistema carcerário dotado de metodologia de execução de pena próprio, criado em 1972 pelo advogado e jornalista Mário Ottoboni, na cidade de São José dos Campos-SP. Conta atualmente com pouco mais de cento e trinta unidades no território nacional ${ }^{2}$, o que corresponde a uma ínfima porcentagem dos sistemas carcerários do Brasil.

A metodologia da APAC, relativamente antagônica ao aplicado nos demais sistemas penitenciários do país, se acopla perfeitamente aos preceitos da Constituição Federal, mais precisamente ao art. $1^{\circ}$, inciso III, que trata da dignidade da pessoa humana e ao art. $5^{\circ}$, XLIX, que assegura aos presos o respeito à integridade física e moral $^{3}$.

A finalidade da APAC é "ajudar o condenado a se recuperar e se reintegrar no convívio social" , e tem como propósito a prevalência dos direitos do condenado sobre o poder punitivo do Estado, colocando-o como destinatário central do método e determinando a família e a sociedade como garantidores e influenciadores diretos do projeto de ressocialização.

Se na relação estatal com o apenado prevalece o poder punitivo remontado pela ideia de perseguição e reducionismo, considerando a pena de prisão como método de isolamento do indivíduo da sociedade por apresentar-se como perigo às relações sociais, na relação proposta pela APAC o que ocorre é justamente o contrário, o delinquente passa a receber amparo para se libertar da mácula do crime.

A remontagem do sistema carcerário passa pelo reconhecimento de que "o Estado já se revelou incapaz de cumprir a função essencial da pena, que é exatamente a de preparar o condenado para retornar à sociedade", o que externaliza a necessidade de transformar a execução

\footnotetext{
${ }^{2}$ De acordo com os dados da Fraternidade Brasileira de Assistência aos Condenados, a APAC tem ao todo cento e vinte unidades no território nacional. (Fraternidade Brasileira de Assistência aos Condenados. APACs Registradas Juridicamente no Brasil. Disponível em: <http://www.fbac.org.br/bdfbac/exibirapacestadobrasil.php?estadodesejado=\&classifica=Todas>. Acesso em: 10 dez. 2019).

${ }^{3}$ BRASIL. Constituição (1988). Constituição da República Federativa do Brasil. Brasília, DF: Senado Federal 1988. Disponível em: <http://www.planalto.gov.br/ccivil_03/constituicao/constituicaocompilado.htm>. Acesso em: $10 \mathrm{dez}$ 2019.

${ }^{4}$ OTTOBONI, Mário. Vamos matar o criminoso?: método APAC. São Paulo: Paulinas, 2001.p.33.

${ }^{5}$ OTTOBONI, Mário; FERREIRA, Valdeci Antônio. Parceiros na ressureição: jornada de libertação com Cristo e curso intensivo de conhecimento e aperfeiçoamento do Método APAC, especialmente para presos. São Paulo: Paulinas, 2004.p.64.
} 
penal em uma atividade integrada à sociedade, afastando o monopólio estatal.

\subsection{MÉTODO DA APAC E SUA RELAÇÃO COM A LEI № 7.210, DE 11 DE JULHO DE 1984}

O método APAC baseia-se em elementos essenciais para a efetivação da recuperação do condenado na execução de pena. Ottoboni ${ }^{6}$ assinala os itens necessários, taxativos e interligados, sem cuja aplicação harmônica não há a possibilidade de lograr êxito na reeducação do preso.

A execução de atividades depende da integração da sociedade, da colaboração de instituições sociais e principalmente da centralização das atividades junto ao preso. Deve-se enumerar as principais fraquezas do indivíduo para que as ações sejam incisivas e encurtem a duração do procedimento.

Por exemplo, se o indivíduo se encontra com distúrbio psicológico, boa parte do período em que se encontra recluso deve ser destinado ao tratamento com psicólogo e psiquiatra, o que significa dizer que o isolamento na cela ou o trabalho penitenciário, comum no sistema penitenciário usual, são exceções e somente poderão ocorrer por recomendação médica e com acompanhamento de um profissional.

Ao contrário do que ocorre no sistema penitenciário comum, em que o indivíduo possui uma rotina que não leva em consideração a sua necessidade físico-psicológica, a APAC se destina ao que de fato prejudica o convívio do indivíduo junto à sociedade. Por essas razões, a efetividade da APAC não é mensurada com dados - reincidência, por exemplo -, mas com o autocontrole constatado por profissionais que demonstram a aptidão do indivíduo para retomar o convívio social.

Classificar o método apaqueano como procedimento integralizado pela Lei de Execuções Penais ${ }^{7}$ depende de uma concatenação

\footnotetext{
${ }^{6}$ São eles: participação da comunidade e da família, controle social penitenciário, confiança no encarcerado, trabalho, educação, apoio religioso para os que professam alguma fé, posto de atendimento médico, consultas regulares ao psicólogo, assistência jurídica (OTTOBONI, op. cit. 2001.p.63).

${ }^{7}$ BRASIL. Lei no 7.210, de 11 de julho de 1984. Institui a Lei de Execução Penal. Diário Oficial da União, Brasília, 13 jul. 1984. Disponível em: <http://www.planalto.gov.br/ccivil_03/leis/ 17210compilado.htm>. Acesso em: 11 dez. 2019.
} 
dos propósitos de ambos. É preciso relacionar os princípios e características pregados, prezando sempre pela uniformidade entre a referida lei e o método APAC.

$\mathrm{O}$ elemento nuclear e essencial da metodologia apaqueana é o mérito. Tal como assinala o art. $33, \S 2^{\circ}$, do $\mathrm{Código} \mathrm{Penal}^{8}$ e o art. 125, parágrafo único, da Lei $\mathrm{n}^{\circ} 7.210^{9}$, é necessário que esse elemento exista para que o condenado mantenha bom comportamento para ter acesso a benefícios, sendo este o primeiro fator de integração ${ }^{10}$.

Outro elemento de suma importância para a efetividade da metodologia da APAC é a assistência ao encarcerado no próprio ambiente carcerário, o que engloba atendimento ambulatorial, consultas regulares a psicólogos e psiquiatras e serviços farmacêuticos. A Lei de Execuções Penais ${ }^{11}$, em seu art. $14, \S 2^{\circ}$, reconhece a precariedade do sistema carcerário brasileiro, que está longe de corroborar com a igualdade material ${ }^{12}$ aduzida pela Constituição Federal ${ }^{13}$.

A generalidade do alcance dos direitos previstos no ordenamento engloba também os reclusos ${ }^{14}$, que dependem de proteção maior do Estado

\footnotetext{
${ }^{8}$ BRASIL. Decreto-Lei no 2.848 , de 07 de dezembro de 1940. Institui o Código Penal. Diário Oficial da União, Rio de Janeiro, 31 dez. 1940. Disponível em: <http://www.planalto.gov.br/ccivil_03/decreto lei/Del2848compilado.htm>. Acesso em: 11 dez. 2019.

${ }^{9}$ BRASIL. op. cit. [Lei no 7.210 (1984)].

${ }^{10} \mathrm{O}$ instituto da progressão de regime é um exemplo que possui o mérito como integrante. Como afirma Rogério Greco: “A progressão é um misto de tempo mínimo de cumprimento de pena (critério objetivo) com o mérito do condenado (critério subjetivo). A progressão é uma medida de política criminal que serve de estímulo ao condenado durante o cumprimento de sua pena. A possibilidade de ir galgando regimes menos rigorosos faz com que os condenados tenham a esperança de retorno paulatino ao convívio social" (GRECO, Rogério. Curso de Direito Penal: parte especial. 6. ed. Niterói: Impetus, 2009. v. 3, p. 512).

${ }^{11}$ BRASIL. op. cit. [Lei $\mathrm{n}^{\circ} 7.210$ (1984)].

${ }^{12}$ Em relação à igualdade material entre pessoas livres e reclusas, o STF, no julgamento do Recurso Extraordinário $\mathrm{n}^{\circ} 267.612$, decidiu da seguinte forma: (...) o direito público subjetivo à saúde representa prerrogativa jurídica indisponível assegurada à generalidade das pessoas pela própria Constituição da República (art. 196). Traduz bem jurídico constitucionalmente tutelado, por cuja integridade deve velar de maneira responsável o Poder Público, a quem incumbe formular - e implementar - políticas sociais e econômicas que visem a garantir, aos cidadãos, o acesso universal e igualitário à assistência hospitalar. (BRASIL. Supremo Tribunal Federal. Recurso Extraordinário no 267.612. Relator: Min. Celso de Mello. Diário de Justiça, Brasília, 23 ago. 2000).

${ }^{13}$ BRASIL, op. cit. [Constituição (1988)].

${ }^{14}$ Como assinala Andrew Coyle: (...) se o Estado assume para si o direito de privar alguém de sua liberdade, por qualquer razão que seja ele também deve assumir para si a obrigação de assegurar que essa pessoa seja tratada de modo digno e humano. $\mathrm{O}$ fato de os cidadãos que não estão presos terem dificuldade de viver com dignidade nunca pode ser usado como justificativa pelo Estado para deixar de tratar aqueles que estão sob seus cuidados de modo digno. Esse princípio reflete o cerne da sociedade democrática, na qual os órgãos do Estado devem ser vistos como exemplos do modo como devem ser tratados todos os cidadãos. (COYLE, Andrew. Administração Penitenciária: uma abordagem de
} 
em razão da condição de hipossuficiência que adquirem em virtude do cárcere.

A família é outro requisito essencial para o sistema carcerário e também para o método apaqueano -, sendo que a sua restrição como forma de sanção disciplinar ao preso (arts. 41, parágrafo único, e 53, inciso III da LEP) pode provocar efeitos drásticos no indivíduo recluso que são contrários à pretensão do sistema corretivo ${ }^{15}$. A família, além de sua importância institucional, adquire junto ao preso a função de conectá-lo ao mundo externo, sendo que o afastamento pode provocar ansiedade, irritabilidade e desânimo.

Conforme dispõe Rodrigo Roig ${ }^{16}$, ainda que fosse considerada uma punição enquadrada na pessoa do indivíduo, a impossibilidade de contato familiar transcenderia à sua pessoa, uma vez que constitui direito dos familiares o contato com o preso, não podendo ser atingidos por uma sanção disciplinar desse porte.

Por fim, tem-se a progressão de regime como requisito metodológico do sistema apaqueano de execução de pena. Como bem explicita Ottoboni ${ }^{17}$, o isolamento típico do regime fechado e o desenvolvimento de atividades rentáveis sem propósito claro no regime penitenciário não são soluções, e sim problemas que permeiam a execução penal. Como bem explicita Robson Carvalho ${ }^{18}$, "o Estado precisa desenvolver ações eficazes que possibilitem a ressocialização de pessoas em privação de liberdade. Atualmente, a ressocialização é um mundo de 'faz-de-contas', e as ações voltadas para este fim quase não existem'.

direitos humanos. Disponível em: <http://www.prisonstudies.org/sites/default/files/resources/ downloads/portugese_handbook.pdf $>$. Acesso em: $11 \mathrm{dez} .2019)$.

${ }^{15}$ A transferência do preso para unidade prisional de outro estado ou município reduz abruptamente o contato familiar, fazendo com que o preso mantenha laços afetivos apenas com outros detentos, o que pode ser um perigo até mesmo para a sociedade. Ottoboni propõe a descentralização do sistema prisional, para que pequenos centros sejam criados em proximidade do local em que o indivíduo reside, favorecendo o contato com os familiares e demais integrantes da sociedade, o que deve ocorrer de forma cautelar (OTTOBONI, op. cit. 2001, p. 53-54).

No tocante à redução do campo social do presídio, oportuno o entendimento de Heleno Fragoso: "A reunião coercitiva de pessoas do mesmo sexo num ambiente fechado, autoritário, opressivo e violento, corrompe e avilta. Os internos são submetidos à lei da massa, ou seja, os códigos dos presos, onde impera a violência e a dominação de uns sobre os outros. (FRAGOSO, Heleno. Lições de Direito Penal: parte geral. São Paulo: Forense, 1992, p. 287-289)".

${ }^{16}$ ROIG, Rodrigo Dutra Estrada. Execução Penal: teoria crítica. 3. ed. São Paulo: Saraiva, 2017. p. 75.

${ }^{17}$ OTTOBONI, op. cit. 2001. p. 74-76.

${ }^{18}$ CARVALHO, Robson Augusto Mata de. Cotidiano encarcerado: o tempo como pena e o trabalho como "prêmio". São Paulo: Conceito Editorial, 2011.p. 138-139. 


\subsection{DO ABRANDAMENTO DO SOFRIMENTO EM VIRTUDE DA PARTICIPAÇÃO SOCIAL E FAMILIAR NA EXECUÇÃO DA PENA}

Com um total de 726.712 presos, segundo apuração mais recente divulgada pelo Ministério da Justiça ${ }^{19}$, a população carcerária brasileira fica à mercê de atos administrativos insuficientes para cumprir o caráter reeducador da pena. O período de cárcere e as atividades que são realizadas pelo corpo administrativo (diretores de presídios, agentes penitenciários, etc.) dão a entender que a missão estatal se pauta em manter o cumprimento de pena, não tendo como valor primordial a reintegração e ressocialização do preso. A lotação de celas e a falta de planejamento, associadas à falta de recursos, impedem que a individualização da pena transpasse a individualização da execução.

Como assinala Fragoso:

A reunião coercitiva de pessoas do mesmo sexo num ambiente fechado, autoritário, opressivo e violento, corrompe e avilta. Os internos são submetidos à lei da massa, ou seja, os códigos dos presos, onde impera a violência e a dominação de uns sobre os outros $^{20}$.

Afastar do contato familiar e social, aceitar o ambiente degradante e desumano no presídio, desvalorizar atividades laborais e educacionais apenas desqualificam o sistema estatal. A segurança passa a ser essencial apenas para os cidadãos civis, não tendo o mesmo valor para aqueles que estão no presídio. Muros altos e vigilância diária servem para manter o indivíduo pressionado, sem procurar entender quais atos administrativos poderiam colaborar com sua integridade e recuperação.

O problema da norma penal é a confiança que as pessoas têm na sua aplicação, acreditando que a punição em si já beneficia a sociedade, uma vez que afasta do convívio social o indivíduo infrator. De acordo com Cezar Roberto Bitencourt:

Não se pode atribuir às disciplinas penais a responsabilidade exclusiva de conseguir a completa ressocialização do delinquente, ignorando a existência de outros programas e meios de controle

\footnotetext{
19 BRASIL. Ministério da Justiça. Há 726.712 pessoas presas no Brasil. Disponível em: <http://www.justica.gov.br/news/ha-726-712-pessoas-presas-no-brasil>. Acesso em: 14 dez. 2019.

${ }^{20}$ FRAGOSO, Heleno. Lições de Direito Penal: parte geral. São Paulo: Forense, 1992.p. 287-289.
} 
social de que o Estado e a sociedade devem dispor com objetivo ressocializador, como são a família, a escola, a Igreja, etc. ${ }^{21}$.

Nota-se que a efetividade da recuperação não é garantida pelo positivismo normativo e pela adequação ao caso concreto. Atribuir uma norma penal a uma situação fática não significa realizar o interesse social de pacificação. Como afirma Claus Roxin ${ }^{22}$, "a readaptação social abrange uma problemática que transcende os aspectos puramente penal e penitenciário".

Indo de encontro a esse problema e percebendo que o sistema estatal demonstrou fraquezas, o método apaqueano ganhou força e revolucionou a interação entre condenado, sociedade e família. Entende-se que há um ciclo entre a conduta do indivíduo e a atuação estatal no combate ao crime. Segundo Ottoboni ${ }^{23}$, a reincidência ocorre pela falta de tratamento eficaz e pela carência de participação da sociedade na execução de pena. A reforma só ocorrerá quando houver descentralização dos presídios, mediante cooperação social e participação de entidades organizadas juridicamente.

Quando o método apaqueano valoriza a família não está se referindo ao simples fato de trazer a convivência com o condenado. Como assinala Ottoboni:

(...) a família do recuperando não pode, em hipótese alguma, estar excluída da metodologia da APAC, uma vez que todos os dados estatísticos nos dão conta de que, entre os fatores da criminalidade, a família comparece com $98 \%$. São os lares desestruturados, em todos os aspectos, que vivem à margem da religião, da ética, da moral, da cultura, etc. Sofrem a exclusão social e acaba, por isso mesmo, se tornando fonte geradora de delinquência. Por esse motivo a família do recuperando precisa receber atenção especial do Método APAC ${ }^{24}$.

Assim, a integridade da família é considerada tão importante quanto o próprio condenado. A família serve como alicerce para a estabilidade emocional, necessitando de elementos mínimos para sua manutenção. $\mathrm{O}$ fornecimento de amparo psicológico, alimentar e

\footnotetext{
${ }^{21}$ BITENCOURT, Cezar Roberto. Tratado de Direito Penal: Parte Geral. 22. ed. São Paulo: Saraiva, 2016.p.608.

${ }^{22}$ ROXIN, Claus. Problemas Fundamentais de Direito Penal. 3. ed. Lisboa: Vega, 2004.p.42-43.

${ }^{23}$ OTTOBONI, op. cit. 2001. p. 37.

${ }^{24}$ OTTOBONI; FERREIRA, op. cit. 2004, p. 86.
} 
educacional aos familiares é fundamental para que o encarcerado se sinta mais sereno durante o processo.

Além disso, distanciar a família de seus problemas corriqueiros, tais como vícios e desavenças, permite que o condenado tenha um ambiente familiar menos propício à criminalidade, sentindo gosto pela manutenção dos vínculos familiares e refletindo sobre os atos que precisará realizar para mantê-la nesse estado.

A família ${ }^{25}$ é considerada uma fonte, um leito que depende de todo conforto e regularidade para conseguir recepcionar aquele que ali se formou. Se esta se encontra decadente, menor a possibilidade de o indivíduo se acomodar e permanecer nesse ambiente.

A sociedade, por sua vez, é interessada mediata pela recuperação do condenado, sendo necessária sua participação. Como afirma Rodrigo Roig:

A assistência aos condenados, provisórios, internados e egressos é exigência básica do Estado de Direito, inclusive para se evitar a ruptura do dialogo entre aqueles e a comunidade, o que somente agravaria a dessocialização já típico do processo de encarceramento ${ }^{26}$.

Se o indivíduo viola uma norma jurídica e imediatamente é retirado do convívio social, entende-se que ele não está apto a se relacionar com outras pessoas. A partir do momento que ele fica recluso, não interfere diretamente na rotina da sociedade.

Contudo, uma pessoa estagnada por anos em um ambiente deteriorante não pode contribuir de forma significativa para a sociedade. Além de ser uma pessoa a mais dependendo de investimento público para sua manutenção, não possui garantias de recuperação. Despejar sobre o Estado de forma absoluta o a execução penal é defender uma ideia utópica de atos administrativos.

A Lei $n^{\circ} 7.210^{27}$, em seu art. $4^{\circ}$, clama pela integração da comunidade, uma vez que esta é o principal componente do Estado. Se há fornecimento de amparo psicológico, material e laboral por parte da

\footnotetext{
${ }^{25}$ Cabe observar que a família é vista do ponto de vista lato, dizendo respeito também à família da vítima. Ottoboni, em relação à assistência da família da vítima diz que "deve haver um departamento próprio formado por voluntários (técnicos e religiosos), para promover essa assistência" (OTTOBONI; FERREIRA, op. cit. 2004, p. 86).

${ }^{26}$ ROIG, op. cit. 2017, p. 161.

${ }^{27}$ BRASIL. op. cit. [Lei no 7.210 (1984)].
} 
sociedade, consequentemente há uma relação de cooperação, em que todos saem satisfeitos. A economia e o mercado de trabalho são favorecidos com o trabalho do preso, há movimentação de dinheiro, de bens e serviços, ao passo que o indivíduo se recupera.

\title{
3 O SISTEMA CARCERÁRIO COMUM À LUZ DA DOUTRINA
}

\subsection{A EXTENSÃO AOS RECLUSOS DOS DIREITOS FUNDAMENTAIS DE PRIMEIRA E SEGUNDA GERAÇÃO}

A Constituição Federal ${ }^{28}$, ao instituir o sistema Democrático de Direito, automaticamente criou limitações ao Estado quanto ao seu poder de agir. Como assinala Mário Lúcio Quintão Soares:

\begin{abstract}
O Estado da Razão (Estado de Direito), assente na premissa de que a razão fundamenta a legislação positiva, deve respeitar a liberdade ética do homem tomado individualmente e reconhecer uma vinculação jurídica para seus próprios atos, visando a coincidir sua finalidade com os fins múltiplos dos indivíduos ${ }^{29}$.
\end{abstract}

Tais restrições refletem no Direito, de forma a garantir o bemestar dos indivíduos no campo jurídico. No direito processual, por exemplo, consolidaram-se o contraditório e a ampla defesa como forma de impedir a atuação discricionária do magistrado, valorizando a atuação das partes $^{30}$ e exigindo a fundamentação de todas as decisões do juiz, conforme disposição do art. 93, IX da $\mathrm{CF}^{31}$. Já na execução penal, o Direito também deve possuir o objetivo de "legitimar as decisões das agências jurídicas, tomadas no intuito de conter racionalmente a ação do poder punitivoexecutório do Estado de Polícia em prol do fortalecimento das bases do Estado de Direito"32.

\footnotetext{
${ }^{28}$ BRASIL, op. cit. [Constituição (1988)].

${ }^{29}$ SOARES, Mário Lúcio Quintão. Direitos Fundamentais e Direito Comunitário. Belo Horizonte: Del Rey, 2000.p.79-80.

${ }^{30}$ DIAS, Ronaldo Brêtas de Carvalho. Processo Constitucional e Estado Democrático de Direito. 3. ed. rev. e ampl. Belo Horizonte: Del Rey, 2015.p.122-135.

${ }^{31}$ BRASIL, op. cit. [Constituição (1988)].

${ }^{32}$ ROIG, op. cit. 2017 , p. 27.
} 
Ante a impossibilidade de superação da pena restritiva de liberdade, sendo esta considerada como "mal necessário" 33 por parte da doutrina, não se pode deixar de olvidar que:

(...) o Estado Republicano e Democrático de Direito brasileiro possui como fundamento a dignidade da pessoa humana (e sua correspondente humanidade das penas), compete aos juristas e às agências jurídicas impedir que a habilitação desmesurada e irracional do poder punitivo e executório - típicos do Estado de Policia - prejudique os objetivos fundamentais de construção de uma sociedade livre, justa e solidária (art. $3^{\circ}, \mathrm{I}, \mathrm{da} \mathrm{CF}$ ), erradicação da marginalização e redução das desigualdades sociais (art. $3^{\circ}$, III, da CF) e promoção do bem de todos (art. $3^{\circ}$, IV, da CF) ${ }^{34}$.

Sendo assim, de modo a obstar o antagonismo derivado do direito à liberdade ante a previsão da pena de prisão, o Estado Democrático de Direito busca mitigar os efeitos do cárcere, evitando que o sistema interfira de forma extrema na liberdade do indivíduo. No ordenamento brasileiro, a $\mathrm{LEP}^{35}$, em seu art. $3^{\circ}$, dispõe que a liberdade do indivíduo é cabível em tudo aquilo que não é atingido pelos efeitos da decisão judicial. Desse modo, mesmo que o condenado esteja recluso, não poderá ser constrangido a realizar atividades contra a sua vontade, como, por exemplo, se expor à fotografia ou filmagem no ambiente carcerário ${ }^{36}$.

Os direitos sociais, assinalados no art. $6^{\circ}$ da Constituição Federal $^{37}$, também são garantidos pelo Estado Democrático de Direito, devendo, em atendimento ao princípio da igualdade, se estender aos $\operatorname{presos}^{38}$.

\footnotetext{
${ }^{33}$ BITENCOURT, Cezar Roberto. Falência da pena de prisão: causas e alternativas. 3. ed. São Paulo: Saraiva, 2004.p.1.

${ }^{34}$ ROIG, Rodrigo Duque Estrada. Aplicação da pena: limites, princípios e novos parâmetros. 2. ed. rev. e ampl. - São Paulo : Saraiva, 2015. p.48.

${ }^{35}$ BRASIL. op. cit. [Lei $\mathrm{n}^{\mathrm{o}} 7.210$ (1984)].

${ }^{36}$ ROIG, op. cit. 2017, p. 134.

${ }^{37}$ BRASIL, op. cit. [Constituição (1988)].

${ }^{38}$ A generalidade doesses direitos está contida na Declaração Universal dos Direitos do Homem de 1948 em seu art. XXII: "todo homem, como membro da sociedade, tem direito à segurança social e à realização, pelo esforço nacional, pela cooperação internacional e de acordo com a organização e recursos de cada Estado, dos direitos econômicos, sociais e culturais indispensáveis à sua dignidade e ao livre desenvolvimento de sua personalidade" (Assembleia Geral da ONU. (1948). Declaração Universal dos Direitos Humanos. (217 [III] A). Paris. Disponível em: <https://www.unicef.org/brazil/pt/resources_10133.htm>. Acesso em: 15 dez. 2019).
} 


\subsection{DA CRISE DA PENA DE PRISÃO}

A prisão foi efetivada como meio punitivo no século XIX com grande expectativa de recuperação do indivíduo infrator, contudo, ao longo dos anos, os métodos utilizados não se mostraram aptos a tal fim, perpetrando uma crise no sistema estatal de execução de pena, com problemas carcerários comuns a todos os países ${ }^{39}$.

A simples prisão, que não procura demonstrar as mazelas do crime e não interfere diretamente na vida social do indivíduo, não é capaz de modificar o pensamento voltado à violação de regras jurídico-criminais.

Ao passar pela pena de prisão o indivíduo se depara com um ambiente hostil e degradante, quando na verdade ele deveria sentir a segurança de um tratamento desenvolvido para que não volte mais a delinquir. A crise no sistema carcerário ocorre justamente porque a punição e a desumanização são elementos presentes na forma estatal de execução de pena, e a recuperação do indivíduo fica em segundo plano $^{40}$, tendo como consequência danos físicos e psicológicos que motivam a realização de rebeliões.

A atuação negativa do Estado no que tange ao bem-estar dos indivíduos encarcerados é reflexo da sociedade, uma vez que impera sobre este meio a visão negativa em ajudar os indivíduos reclusos. Vinculados ao interesse público majoritário, os governantes priorizam outros segmentos sociais, refletindo na precariedade do sistema carcerário ${ }^{41}$.

O que o método APAC procura é justamente ir ao contrário dessa pacificação ideológica, entendendo que o amparo a quem está preso é necessário para o interesse da sociedade, sendo uma metodologia capaz de servir de alicerce enquanto não há uma forma substitutiva à pena de prisão.

\footnotetext{
${ }^{39}$ BITENCOURT, Cezar Roberto. Falência da pena de prisão: causas e alternativas. 3. ed. São Paulo: Saraiva, 2004.p.153-154.

${ }^{40}$ Bitencourt afirma que “(...) fala-se da crise da prisão, mas não como algo derivado estritamente de sua essência, mas como resultado da deficiente atenção que a sociedade e, principalmente, os governantes têm dispensado ao problema penitenciário, o que nos leva a exigir uma série de reformas, mais ou menos radicais, que permitam converter a pena privativa de liberdade em meio efetivamente reabilitador". (BITENCOURT, Cezar Roberto. Falência da pena de prisão: causas e alternativas. 3. ed. São Paulo: Saraiva, 2004.p.157).

${ }^{41}$ GRECO, Rogério. Direitos humanos, sistema prisional e alternativas à privação de liberdade. São Paulo: Saraiva, 2013. p.302.
} 


\subsection{ABOLICIONISMO PENAL: EXTREMISMO LIBERTÁRIO DERIVADO DA ANÁLISE CRÍTICA DA PENA}

Reflexões abolicionistas se deram em diversos momentos da história, mas a teoria propriamente dita surgiu no período pós Segunda Guerra Mundial, tendo como objeto de estudo as formas de controle e de punição impostas pelos regimes que imperavam no mundo na primeira metade do século XX, tais como fascismo, nazismo, socialismo e liberalismo ${ }^{42}$.

É uma ideologia libertária voltada à ampliação da liberdade e da maior autonomia particular dos indivíduos, refutando o poder estatal de punir e transferindo à discussão privada as reparações e consequências da conduta de uma das partes.

Desenvolveu-se em um período em que a disciplina e o medo pairavam como consequência dos regimes autoritários que dominaram a Europa, o que levou alguns autores a formular ideias capazes de conscientizar os indivíduos dos aspectos negativos da pena. Os abolicionistas não procuram uma reforma penal de humanização das penas, mas a sua extinção da consciência humana, tornando-a fora de cogitação.

Tem como principais idealizadores Louk Hulsman, Nils Christie e Thomas Mathiensen, que tiveram perspectivas diferentes do mesmo fundamento ${ }^{43}$.

$\mathrm{O}$ primeiro autor considera que as finalidades preventivas e educativas das penas não têm eficácia, sendo utilizadas para dominações e implantações de sistemas em que o mais poderoso mantém suas bases e evita qualquer ascensão da camada divergente. Corrobora também tal sistemática, de acordo com o autor, para um apego a situações pretéritas, uma vez que condutas são punidas após longos anos de seu acontecimento.

\footnotetext{
${ }^{42}$ De acordo com Edson Passetti, o abolicionismo penal é uma vertente libertária que investe na crítica à punição e que encontrou, no século XX, soluções livres de utopias, presentificando a atuação. Obteve ressonâncias a partir da II Guerra Mundial para acuar o direito penal e questionar os princípios de uma sociabilidade autoritária pautada na centralidade de poder. Pretende discutir a discursividade penalizadora ancorada numa profusão de reformas que atestam e publicizam a inoperância da melhor punição e de seus efeitos disciplinares e de controle, segundo o fluxo contrário ao do "ruim com, pior sem" (PASSETTI, Edson. Sociedade de controle e abolição da punição. São Paulo Perspec. São Paulo, v. 13. n. 3. jul./set. 1999. Disponível em: <http://www.scielo.br/scielo.php?script=sci_arttext\&pid $=$ S0102-88391999000300008\&lng $=\mathrm{pt} \& \mathrm{t} \operatorname{lng}=\mathrm{pt}>$. Acesso em: 04 jan. 2020).

${ }^{43}$ SILVA, Luciano Nascimento. Ensaio acerca da perda de legitimidade do sistema de Justiça Criminal. 2002. Disponível em: <http://www.egov.ufsc.br/portal/sites/default/files/anexos/1361313614-1-PB.pdf>. Acesso em: 04 jan. 2020.
} 
Sentenças penais condenatórias acabam por interferir diretamente na vida dos indivíduos envolvidos, sendo que em alguns casos autor e vítima sequer recordam dos fatos e ambos não têm interesse de discuti-lo juridicamente. Assim, para Hulsman, citado por Erika Dmitruk:

(...) o Direito Penal olha sempre para trás, para o conflito que já aconteceu, e, muitas vezes, com a lentidão do sistema judiciário, muitos conflitos que já estavam solucionados na vida cotidiana são reavivados por citações, audiências e intervenção policial. Segundo o autor é necessário aprender com as comunidades primitivas, que resolvem seus conflitos voltados para o futuro, tentando melhorar a situação da vítima e resolver o seu problema atual, e não apenas saciar um desejo vingativo sobre o fato acontecido ${ }^{44}$.

Hulsman considera que, para a correção do dano causado, outras formas, que não a punição, têm eficácia. Desenvolveu três modelos capazes de sobrepor a pena: o modelo educativo, em que o Estado deverá arcar com políticas preventivas do delito; o modelo conciliatório, em que os indivíduos ligados ao fato deverão encontrar uma solução de forma pacífica; e o modelo compensatório, em que o Estado, por meio da atividade jurisdicional não punitivista, encontrará uma solução ao fato ${ }^{45}$.

Já para Thomas Mathiensen ${ }^{46}$, a teoria abolicionista visa acabar com o sistema de controle capitalista que, segundo ele, se apodera do sistema penal, principalmente do privativo de liberdade, para manter a sobressaída da classe dominante sobre as classes sociais mais pobres.

Nils Christie ${ }^{47}$, por sua vez, entende que a pena é uma forma de provocar sofrimento físico e psíquico no indivíduo, indo contra o viés humanista que seria necessário para garantir o bem-estar de todos os cidadãos. Entende que o crime não existe, sendo um rótulo imposto a determinadas condutas para considerar determinados indivíduos como criminosos e possibilitar sua opressão e controle.

Christie entende que determinadas condutas consideradas como delitos pela sociedade podem ocorrer também no ambiente familiar, não produzindo determinados rótulos em quem o comete, dando a entender, o

\footnotetext{
${ }^{44}$ HULSMAN apud DMITRUK, 2005, p. 64.

${ }^{45}$ PASSETTI, Edson. Ensaio sobre um abolicionismo penal. Revista Semestral Autogestionária do NuSul. $\quad$ n. $9 . \quad 2006 . p .109 . \quad$ Disponível <https://revistas.pucsp.br/index.php/verve/article/view/5131/3658>. Acesso em: 04 jan. 2020.

${ }^{46}$ MATHIENSEN apud PINTO, 2008.

${ }^{47}$ CHRISTIE, Nils. Uma razoável quantidade de crime. Trad. André Nascimento. Rio de Janeiro: Revan, 2011.p.29.
} 
autor, que criminalizar algo parte do subjetivismo de quem interpreta no bojo da sociedade ${ }^{48}$.

A filosofia abolicionista compreende o poder punitivo como um antagonismo ao princípio da liberdade, entendendo que não se pode levar como característica intrínseca da sociedade o poder do castigo. A conduta atípica deve ser levada como um problema que necessita de reparos, em que vítima e autor deveriam conciliar nos moldes do direito civil ${ }^{49}$.

A análise filosófica dessa teoria traduz um extremismo em relação à ideologia penal que paira sobre as sociedades, prezando pela individualização dos casos concretos à tipificação penal. Nesse compasso, nota-se que a resolução de conflitos teria como base a reparação, e não caráter punitivo ou ressocializador.

Constata-se que a evolução punitiva do Estado possibilitou diferentes formas de controle social, não sendo necessário o recolhimento em prisões para que o indivíduo sofra restrições. No entanto, nenhuma dessas contenções foi eficaz a ponto de evitar os avanços da criminalidade.

No período Romano os castigos físicos eram recorrentes; na Revolução Francesa a decapitação por guilhotina, um ato de exemplo; nos Estados Unidos a pena de morte, um aniquilamento do ofensor. Todas essas formas de pena fracassaram, mas em nenhum momento foi cogitada a abolição do sistema penal. Novas formas foram surgindo e sempre se procurou limitar a atuação do indivíduo na sociedade a partir de uma sanção.

Restringir direitos e estabelecer deveres ao indivíduo não são as melhores formas de exigir que após aquelas medidas corretivas ele não venha a delinquir, prova disso é que cada vez mais a prisão demonstra ser um reflexo da sociedade.

Torna-se frutífera a reparação da ofensa e a continuidade posterior da relação civil, contendo os avanços estatais de aplicação de penas que não são capazes de sustar a conduta a prática de crimes. Necessário, de acordo com a visão abolicionista, o afastamento de tudo aquilo que criminalize ou puna qualquer pessoa pelo simples fato de não ter consequência positiva.

Contudo, a mudança precisa ser de ordem moral e comportamental, em que os juristas passem a prezar pelo declínio de

\footnotetext{
${ }^{48}$ CHRISTIE, Nils. A indústria do controle do crime. Rio de Janeiro: Forense, 1998.p.13.

${ }^{49}$ PASSETTI, Edson. Op.cit.p.84.
} 
entendimentos repressivos, valorizando condutas que garantam a liberdade. São nesses núcleos, tais como o jurídico, que são disseminadas as valorizações humanas e as garantias que a pena não é método a ser aplicado na sociedade para reparação de indivíduos.

Percebe-se que tem sido valorizado tal entendimento quando o direito penal passa a contemplar o princípio da ultima ratio, consolidando o entendimento de que o direito penal se encontra no campo mais profundo de todas as áreas jurídicas. Desse modo, verifica-se que apenas bens jurídicos de suma importância são tutelados por esse aparato normativo.

Entretanto, a redução de atuação do direito penal não é o bastante para o abolicionismo, havendo a necessidade de deslocar a tutela de bens jurídico-penais para o âmbito cível, tendo como finalidade a integração das partes na resolução do conflito.

\section{APERFEIÇOAMENTO DA EXECUÇÃO PENAL DECORRENTE DO USO DO MÉTODO DA APAC}

Viu-se que a APAC possui um método de execução de pena singular, que centraliza figura do indivíduo encarcerado e permite a readequação social. Da mesma forma, viu-se que as penitenciárias, embora de difícil superação no âmbito prático, externalizam sofrimento e são reconhecidas pela doutrina como instituições falidas, sem eficácia para as relações sociais.

Sabe-se, também, que o abolicionismo penal é utópico, uma vez que o controle social necessita da aplicação da sanção.

Nesses termos, a melhor solução é a readequação do sistema carcerário, passando por um método mais efetivo, antagônico ao que as penitenciárias comuns têm aplicado.

Preza-se, nesse sentido, pela integração do método da APAC ao sistema penitenciário brasileiro, permitindo que o preso tenha um tratamento mais efetivo e qualificado, com certa visibilidade e apoio popular.

No entanto, essa expansão da aplicação do método da APAC, dado o tratamento protecionista e confortável ao preso, depende de mudança política, legislativa, ética e jurídico-cultural, uma vez que o 
sistema penal é visto pelos brasileiros como uma possibilidade de vingança social $^{50}$.

Antes de tudo, a reforma legislativa deveria reduzir o âmbito de aplicação do Direito Penal, principalmente em relação aos crimes punidos com pena restritiva de liberdade, mantendo esta espécie de pena apenas para os delitos praticados contra os bens jurídicos mais relevantes.

A reforma jurídico-cultural seria possível através de reiteradas práticas tendentes a evitar qualquer forma de abuso na aplicação e na execução da pena. Seria uma valorização conjunta da liberdade e da ordem civil. A decisão judicial passaria a versar sobre reparações necessárias ao caso concreto, não sendo possível a aplicação da sentença com o único intuito de castigar as pessoas por erros que não tenham mais sentido na data em que houve a apreciação judicial. Os autores de crimes de maior reprovação deveriam passar pelo sistema carcerário nos moldes garantistas da Lei e através do método da APAC, com o único propósito de recuperação.

Conforme assinalado anteriormente, a Lei $\mathrm{n}^{\mathrm{o}} 7.210^{51}$ possui compatibilidade com o método apaqueano de diversas formas, mas não há adoção integral dessa filosofia que se mostrou frutífera na recuperação de indivíduos encarcerados. De uma forma gradual a APAC chamou atenção da população, seja de uma forma positiva, através do baixo índice de reincidência de quem sofreu processo de recuperação em seus Centros de Reintegração, seja de forma negativa quanto àqueles que consideram que o cárcere deve ser um ambiente propício ao sofrimento humano.

Tal fato fez com que o poder público se rendesse - ao menos de forma parcial - aos preceitos dessa ideologia, tornando a APAC uma ferramenta de atuação conjunta com os Poderes Executivo e Judiciário. É uma iniciativa precisa e ousada, ao passo que o sistema penal sempre foi uma forma de controle exclusivo do Estado, não se imaginando, até pouco tempo atrás, que uma entidade privada teria tamanha importância na execução penal.

\footnotetext{
${ }^{50}$ Como afirma Ney Moura Teles, "nos dias de hoje, com enorme e preocupante aumento da criminalidade violenta e organizada, assiste-se à tentativa de transformar o Direito Penal no salvador da pátria, como se ele fosse capaz de eliminar o crime e transformar os homens. O legislador brasileiro, ultimamente, tem acenado com a exasperação de penas, criação de novas figuras de crime, com a restrição de direitos e garantias processuais, como se isso resolvesse alguma coisa". (TELES, Ney Moura. Direito Penal: parte geral. 2. ed. São Paulo: Atlas, 2006.p.06).

${ }^{51}$ BRASIL. op. cit. [Lei no 7.210 (1984)].
} 
Todavia, essa abertura dada pelo Estado é gradativa, permanecendo este com autonomia para afastar a interferência privada e manter a forma frágil e antiética de aplicação de pena, que já se demonstrou fracassada com o passar dos anos.

O que se preconiza é a adoção de forma positivada do método APAC. Somente desse modo o poder público estaria obrigado a observar a metodologia, nos moldes do Estado Democrático de Direito. Para isso, são necessárias mudanças legislativas, principalmente na Lei de Execução Penal, de forma a abranger a sistemática.

\section{CONSIDERAÇÕES FINAIS}

Tendo em vista o conteúdo supramencionado percebe-se que a pena de prisão se encontra em decadência. A manipulação pelo Estado e as várias interferências políticas contribuíram para que o sistema de correção perdesse o seu valor. Ao longo da história a ideologia por trás da pena foi se alterando, justificando a imposição para que a sociedade mantivesse a sua ordem.

Ao que tudo indica, a prisão é o "mal necessário" que possibilita a paz social, mediante um sistema estatal que zela pela ordem pública, mas seria essa uma justificativa científica ou uma mera opinião que tenta justificar o controle social, assim como entende Foucault ${ }^{52}$ ? Certo é que, independentemente da justificativa, diversas classes se utilizaram da punição para fazer valer o seu poder, para não haver a equiparação dos direitos, e para que se dividissem os cidadãos entre os protegidos e perseguidos.

Foucault ${ }^{53}$ estabeleceu as justificativas históricas das penas, e os libertários criticaram de forma contundente os efeitos que elas causam no indivíduo e naqueles que o rodeiam. Na verdade, o sistema punitivo só se mantém pela necessidade que os indivíduos têm de controlar e manipular a conduta dos demais, porque ninguém se imagina no polo passivo da aplicação de pena, crendo sempre que é uma medida um tanto quanto distante de sua realidade.

\footnotetext{
${ }^{52}$ FOUCAULT, Michel. Vigiar e Punir: nascimento da prisão. 36 ed. Petrópolis: Vozes, 2009.

${ }^{53}$ Idem, p. 13.
} 
Essa diferenciação entre os sujeitos encarcerados e os demais começou a mudar quando o Estado Democrático de Direito estabeleceu a valorização do indivíduo, sem levar em consideração suas características, possuindo direitos pelo simples fato de pertencer à espécie humana. Aos poucos foram sendo estendidos os direitos dos cidadãos àqueles que se mostraram incapazes de obedecer às regras jurídicas, tratando-os com mais dignidade no execrável ambiente da prisão.

O método de aplicação de pena que mais valoriza o princípio da dignidade da pessoa humana no âmbito da execução penal é o difundido pela APAC, demonstrando que quanto mais humano o tratamento maior o benefício que ele traz, remontando todo o sistema em vigor no Estado e ganhando destaque a ponto de atuar concomitantemente com este. A execução de pena, fundado nos princípios difundidos pela APAC, assim como os direitos fundamentais pregados pela Constituição, deve ser inerente ao poder político, não podendo variar quanto aos interesses de parlamentares.

Nesse sentido, instituir uma norma federal nos ditames de execução de pena da APAC, é a solução para recuperar a pena de prisão, valorizando a família, o trabalho e a assistência social, acompanhando o processo evolutivo da sociedade. Ao invés de ser destinada ao controle do indivíduo encarcerado, a Lei se voltará ao próprio Estado, tornando-o obrigado a estabelecer uma estrutura compatível com os direitos humanos.

\section{REFERÊNCIAS BIBLIOGRÁFICAS}

Assembleia Geral da ONU. (1948). Declaração Universal dos Direitos Humanos. (217 [III] A). Paris. Disponível em: <https://www.unicef.org/brazil/pt/resources_10133.htm>. Acesso em: 15 dez. 2019.

BITENCOURT, Cezar Roberto. Falência da pena de prisão: causas e alternativas. 3. ed. São Paulo: Saraiva, 2004.

Tratado de Direito Penal: Parte Geral. 22. ed. São Paulo: Saraiva, 2016.

BRASIL. Constituição (1988). Constituição da República Federativa do Brasil. Brasília, DF: Senado Federal, 1988. Disponível em:

<http://www.planalto.gov.br/ccivil_03/constituicao/constituicaocompilado.htm>. Acesso em: $10 \mathrm{dez}$ 2019.

BRASIL. Decreto-Lei no 2.848, de 07 de dezembro de 1940. Institui o Código Penal. Diário Oficial da União, Rio de Janeiro, 31 dez. 1940. Disponível em: 
<http://www.planalto.gov.br/ccivil_03/decreto lei/Del2848compilado.htm>. Acesso em: 11 dez. 2019.

BRASIL. Lei no 7.210, de 11 de julho de 1984. Institui a Lei de Execução Penal. Diário Oficial da União, Brasília, 13 jul. 1984. Disponível em:

<http://www.planalto.gov.br/ccivil_03/leis/17210compilado.htm>. Acesso em: 11 dez. 2019.

BRASIL. Ministério da Justiça. Há 726.712 pessoas presas no Brasil. Disponível em:

<http://www.justica.gov.br/news/ha-726-712-pessoas-presas-no-brasil>. Acesso em: 14 dez. 2019.

BRASIL. Supremo Tribunal Federal. Recurso Extraordinário nº 267.612. Relator: Min. Celso de Mello. Diário de Justiça, Brasília, 23 ago. 2000.

CARVALHO, Robson Augusto Mata de. Cotidiano encarcerado: o tempo como pena e o trabalho como "prêmio". São Paulo: Conceito Editorial, 2011.

COYLE, Andrew. Administração Penitenciária: uma abordagem de direitos humanos. Disponível em: 〈http://www.prisonstudies.org/sites/default/files/resources/downloads/portugese_handbook.pdf $>$. Acesso em: $11 \mathrm{dez} .2019$.

CHRISTIE, Nils. A indústria do controle do crime. Rio de Janeiro: Forense, 1998.p.13.

CHRISTIE, Nils. Uma razoável quantidade de crime. Trad. André Nascimento. Rio de Janeiro: Revan, 2011.

DIAS, Ronaldo Brêtas de Carvalho. Processo Constitucional e Estado Democrático de Direito. 3. ed. rev. e ampl. Belo Horizonte: Del Rey, 2015.

DMITRUK, Erika Juliana. Que é o Abolicionismo Penal?. Revista Jurídica da UniFil. n. 2, 2005. Disponível em: <http://web.unifil.br/docs/juridica/03/Revista\%20Juridica_03.pdf\#page=59>. Acesso em 04 jan. 2020.

DOS SANTOS, Juarez Cirino. O direito penal do inimigo - ou o discurso do direito penal desigual. 2012. Disponível em: <http://icpc.org.br/wp-

content/uploads/2012/05/direito_penal_do_inimigo.pdf >. Acesso em: $10 \mathrm{dez} .2019$

FOUCAULT, Michel. Vigiar e Punir: nascimento da prisão. 36 ed. Petrópolis: Vozes, 2009.

FRAGOSO, Heleno. Lições de Direito Penal: parte geral. São Paulo: Forense, 1992.

Fraternidade Brasileira de Assistência aos Condenados. APACs Registradas Juridicamente no Brasil. Disponível em: <http://www.fbac.org.br/bdfbac/exibirapacestadobrasil.php?estadodesejado $=\&$ classifica=Todas $>$. Acesso em: 10 dez. 2019.

GRECO, Rogério. Curso de Direito Penal: parte especial. 6. ed. Niterói: Impetus, 2009. v. 3. Saraiva, 2013.

Direitos humanos, sistema prisional e alternativas à privação de liberdade. São Paulo: 
OTTOBONI, Mário; FERREIRA, Valdeci Antônio. Parceiros na ressureição: jornada de libertação com Cristo e curso intensivo de conhecimento e aperfeiçoamento do Método APAC, especialmente para presos. São Paulo: Paulinas, 2004.

OTTOBONI, Mário. Vamos matar o criminoso?: método APAC. São Paulo: Paulinas, 2001.

PASSETTI, Edson. Ensaio sobre um abolicionismo penal. Revista Semestral Autogestionária do NuSul. n. 9. 2006.p.109. Disponível em:

<https://revistas.pucsp.br/index.php/verve/article/view/5131/3658>. Acesso em: 04 jan. 2020.

Sociedade de controle e abolição da punição. São Paulo Perspec. São Paulo, v. 13. n. 3.

jul./set. 1999. Disponível em: <http://www.scielo.br/scielo.php?script=sci_arttext\&pid=S0102$88391999000300008 \& \operatorname{lng}=$ pt\&tlng=pt $>$. Acesso em: 04 jan. 2020.

PINTO, Carlos Alberto Ferreira. O abolicionismo penal. 2008. Disponível em:<http://www.buscalegis.ufsc.br/revistas/files/anexos/13648-13649-1-PB.pdf>. Acesso em: 12 mai. 2018.

ROIG, Rodrigo Dutra Estrada. Execução Penal: teoria crítica. 3. ed. São Paulo: Saraiva, 2017.

Saraiva, 2015.

. Aplicação da pena: limites, princípios e novos parâmetros. 2. ed. rev. e ampl. - São Paulo :

ROXIN, Claus. Problemas Fundamentais de Direito Penal. 3. ed. Lisboa: Vega, 2004.

SILVA, Luciano Nascimento. Ensaio acerca da perda de legitimidade do sistema de Justiça Criminal. 2002. Disponível em: <http://www.egov.ufsc.br/portal/sites/default/files/anexos/1361313614-1-PB.pdf>. Acesso em: 04 jan. 2020.

SOARES, Mário Lúcio Quintão. Direitos Fundamentais e Direito Comunitário. Belo Horizonte: Del Rey, 2000.

TELES, Ney Moura. Direito Penal: parte geral. 2. ed. São Paulo: Atlas, 2006. 